\title{
JURNAL
}

\section{PENELITIAN dan PENGEMBANGAN}

\section{PENDIDIKAN ANAKUSIA DIN}

JPPPAUD Tahun 2, Nomor 3, September 2015
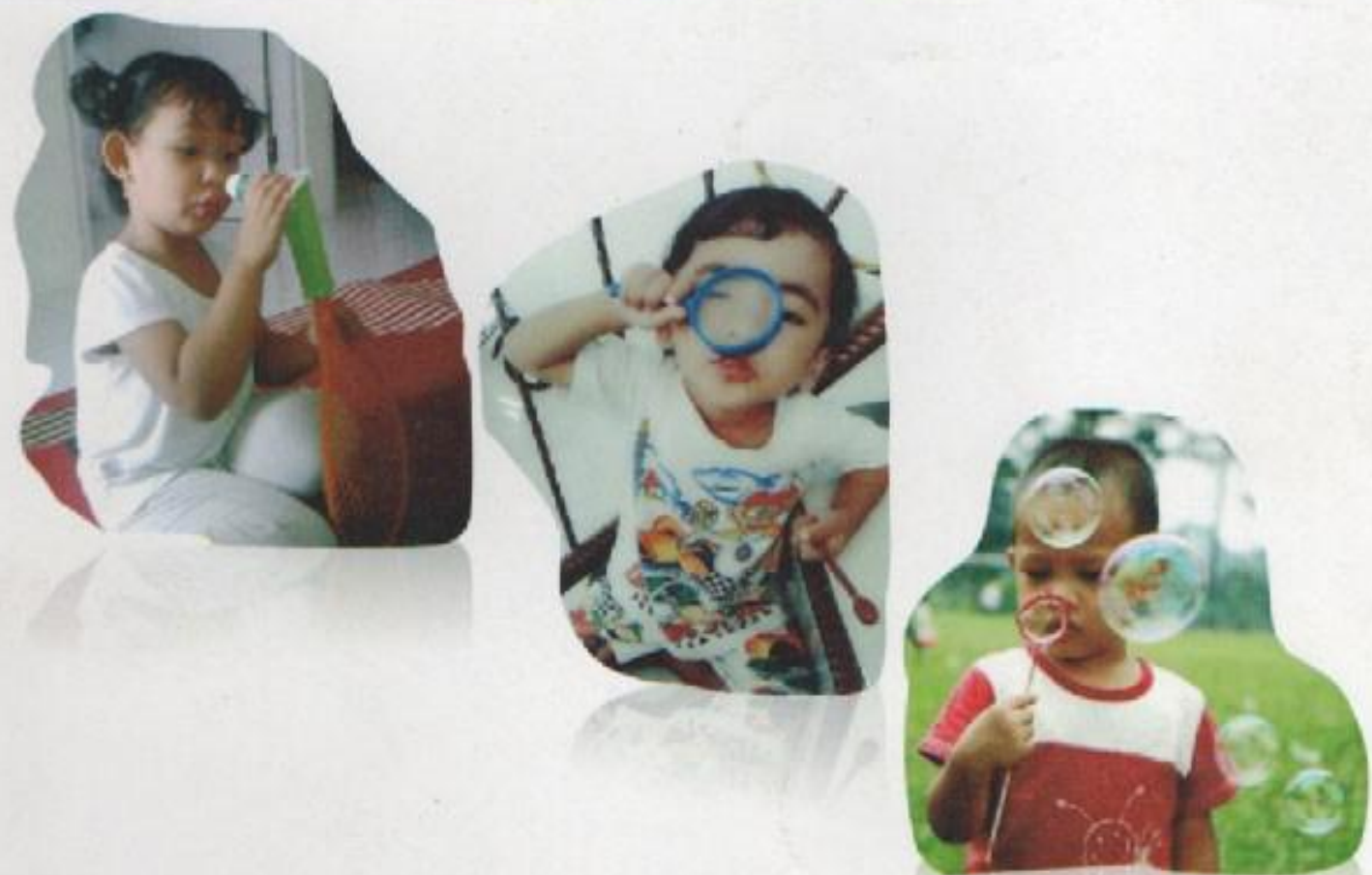

Diterbitkan oleh:

Jurusan Pendidikan Guru Pendidikan Anak Usia Dini

Fakultas Keguruan dan IImu Pendidikan

Universitas Sutan Ageng Tirtayasa 


\title{
MENINGKATKAN KEMAMPUAN MEMBACA PERMULAAN SISWA SD KELAS I MELALUI PENDEKATAN WHOLE LANGUAGE FAHRURROZI
}

\author{
email : Fahrurrozi_unj@yahoo.com
}

\section{Universitas Negeri Jakarta}

\begin{abstract}
Abstroct. Earty reading ability is the ability of students in sounding symbol's in the form of letters and numbers using voice loud and ciear. Eariy reading purpases in adidion that the childwen are able to recognize letiers, wanks, and sentences well also train gross motor skills of children, especially phonology. So chat children are able to read the beginning of the fast, the need for effective learning approach to improve the ability to read the beginning One learning approaches that can be used to enhance tire ability recognize letters, wandr and sentences is a whole language approach. Whole language is an approach that integrates four aspects of language skills into learning indonerian. Be integrated with the teaching of rading writing, listening and speaking. Whole language approach is an approach where all aspects of language skills in the learning process we internelated to ane another: On learning this, the doninant student to learn independently: Students are placed as a subject not an object. The role of the teacher in learning the whole language approach only a focilitator. Teachers in charge of guiding and directing in a problew-solving.
\end{abstract}

Keywords : Reading ability starters, the whole language approach

Abstrak. Kemampuan membaca permulaan adalah kesanggupan siswa dalam membunyikan simbol-simbol yang berupa huruf dan angka dengan menggunakan suara yang nyaring dan jelas. Tuiuan membaca permulaan di sumping agar anak mampn mengenal huruf, kata, dan kalimat dengan baik juga melatih motorik kasar anak terumama fonologi. Agar anak mampu membaca permulaan dengan cepat maka perlu adanya pendekatan pernbelajaran yang efektif untuk meningkatkan kemampuan membaca permulaan tersebut. Salah satu pendekatan penbelajaran yang dapat digunakan untuk meningkatkan kemampuan mengenal huruf, kata dan kalimat adalah pendekatan whole language. Whole language adaiah sebuah pendekatan yang mengintegrasikan keempat aspek keterampilan berbahasa ke dalam pembelajaran bahasa Indonesia. Pengaiaran meinhaea dintegrasikan dengan menulis, menyimak dan berbicara. Pendekatan whole language merupakan sebuah pendekatan yang mana semua aspek keterampilan berbahasa dalam proses belajar saling berkaitan satu dengan yang lainnya. Pada proses pembelajaran ini, siswa dominan untuk belajar mandiri. Siswa ditempatkan sebagai subjek bukan objek. Peranan guru dalam pembelajaran dengan pendekatan whole language hanya menjadi fasilisator. Guru bertugas untuk membimbing dan mengarahkan dalam suatu pemecahan musalah.

Kata Kunci : Kemampuan Membaca permulaan, Pendekatan whole langaage 


\section{A. Pendahuluan}

Pembelajaran bahasa Indonesia di sekolah dasar (SD) terbagi ke dalam dua jenis pembelajaran, yaitu pembelajaran bahasa Indonesia kelas rendah dan pembelajaran bahasa Indonesia kelas Tinggi. Pembelajaran bahasa Indonesia kelas rendah terkait dengan kompetensi atau keterampilan yang melatih siswa untuk dapat melaksanakan aktivitas motorik kasar seperti membaca nyaring, menulis indah, menceritakan sebuah cerita, dan menyimak cerita secara baik dan benar sebagai bekal siswa dalam memasuki tahap penbelajaran kelas tinggi. Berbeda dengan pembelajaran bahasa Indonesia kelas tinggi yang tujuan adalah membekali siswa dengan kompetensi pengetahuan kebahasaan seperti: membaca pemahaman, mengarang, berpidato, dan menyimak untuk dapat menceritakan cerita yang di dengar sebagai bekal dalam menguasai keterampilan berbahasa pada tingkat pendidikan berikutnya.

Sebagai bagian dari pembelajaran bahasa Indonesia di SD, pembelajaran bahasa Indonesia di kelas rendah merupakan kompetensi awal yang harus dikuasai oleh siswa sebelum siswa mempelajari bidang studi atau pengalaman belajar lainnya. Pada saat siswa pertama sekali memasuki pendidikan di SD di kelas I maka ia akan dikenalkan dengan pembelajaran membaca, menulis, dan berhitung (Calistung). Calistung diajarkan dengan harapan siswa dapat mengenal huruf, kata, kalimat dengan benar dan dapat menuliskannya dengan rapi dan jelas.

Sehubungan dengan itu, dan begitu pentingnya pembelajaran calistung khususnya pembelajaran mem- baca permulaan di kelas I SD, maka diperlukan adanya pendekatan pembelajaran yang efektif dalam tepat yang dapat digunakan oleh guru dalam mengajarkan membaca permulaan. Pembelajaran membaca permulaan di kelas I meliputi materi pengenalan huruf, pengenalan suku kata, pengenalan kata, dan pengenalan kalimat. Semua materi tersebut diharapkan dapat dituntaskan oleh guru dalam waktu yang singkat supaya siswa dapat mempelajari berbagai materi pembelajaran yang lain.

Berdasarkan observasi awal terhadap pembelajaran membaca permulaan di SD ditemukan masih banyak siswa yang belum dapat membaca secara lancar padahal siswa tersebut sudah memasuki semester kedua di kelas 1. Hal ini terlihat dari beberapa anak mengalami kesulitan untuk mengingat simbol huruf, kesulitan membaca huruf yang masih abstrak, dalam membaca huruf masih sering tertukar. Sehubungan dengan itu, diperlukan pendekatan pembelajaran membaca permulaan yang disenangi oleh anak dan yang terpenting harus sesuai dengan karakteristik dan perkembangan anak.

Salah satu pendekatan pembelajaran yang efektif dalam pembelajaran membaca permulaan adalah pendekatan whole language. Whole language merupakan sebuah pendekatan di mana kompetensi-kompetensi berbahasa saling dihubungan disaat pembelajaran berlangsung schingga di dalam pembelajaran tersebut dapat mencapai tujuan yang telah ditentukan dalam proses belajar mengajar di sekolah secara optimal.

\section{B. Kajian Teoritis}

\section{Membaca Permulaan}

Membaca merupakan salah satu ketrampilan yang sangat penting dalam kehidupan bermasyarakat.Menurut Rebeck dan Wilson seperti yang dikutip oleh Sabarti (1998:37), membaca merupakan proses penerjemahan dari kata dan lambang-lambang ke dalam maknanya serta penanda makna baru ke dalam sistim kognitif dan afektif yang sudah dimiliki pembaca. Dapat dijelaskan bahwa pada prinsipnya membaca merupakan kegiatan yang dilakukan oleh seseorang dalam memaknai informasi yang tertulis dalam bacaan untukmengetahuia tujuan informasi tersebut. Kegiatan membaca memerlukan adanya sinergi antara pengetahuan dan sikap pembaca terhadap apa yang di baca.

Membaca permulaan merupakan kegiatan yang menekankan pada proses penyandian membaca secara mekanikal (fisik). Menbaca permulaan merupakan proses recoding dan decoding (Anderson, 1972:209). Membaca merupakan suatu proses yang bersifat fisik dan psikologis. Proses yang bersifat fisik berupa kegiatan mengamati tulisan secara visual dan membunyikan tulisan tersebut dengan menggunakan suara yang nyaring. Dengan indera visual, pembaca mengenali dan membedakan gambar-gambar bunyi serta kombinasinya. Melalui proses recoding, sedangkan proses decoding terkait dengan bagaimana pembaca mengasosiasikan gambar gambar bunyi beserta kombinasinya itu dengan bunyibunyinya untuk dapat dibunyikan dengan intonasi yang jelas.

Selanjutnya, Dawkins dalam Subyantoro (2001:36) memaparkan batasan membaca permulaan yang sederhana, yakni menyuarakan lambang-lambang atau huruf yang tercetak dengan benar. Batasan ini hanya terbatas pada kegiatan membaca permulaan. Penjelasan diatasmengindikasikan bahwa pembaca pemulalah yang biasanya menyuarakan lambang-lambang tertulis dengan suara yang jelas dan intonasi yang tepat Dengan kata lain, kegiatan membaca permulaan berguna untuk membina anak yang baru mulai belajar membaca yaitu 


\section{B. METODE PENELITIAN}

mengenal huruf, suku kata, kata, dan kalimat.

Membaca permulaan adalah membaca yang diajarkan secara terpadu, yang menitik beratkan pada pengenalan hurur dan kata, menghubungkannya dengan bunyi (Dhieni, 2005:5.5). Selanjutnya untuk dapat terampil dalam membaca permulaan sebaiknya siswa dis. timulasi dulu secara bertahap. Stimulasi secara bertahap ini dilakukan untuk sebagai pembiasaan bagi anak dalam membaca. Pembiasaan membaca tersebut dimulai melalui tahap, yakni pramembaca dan membaca. Pada tahap pramembaca kepada anak diajarkan sebagai berikut: : (1) sikap duduk yang baik pada waktu membaca; (2) cara meletakkan buku di meja; (3) cara memegang buku; (4) cara membuka dan membalik halaman buku; dan (5) melihat dan memperhatikan tulisan (Zuchdi, 1996:6). Pembelajaran menbaca permulaan dititik beratkan pada aspek-aspek yang bersifat teknis seperti ketepatan menyuarakan tulisan, lafal dan intonasi yang wajar, kelancaran dan kejelasan suara.

Membaca bukan hanya sekedar membaca, tetapi aktivitas yang mempunyai tujuan yaitu mendapatkan sejumlah informasi baru. Mark Twain mengatakan "The man who does not read good books has no advantage over the man who cannot read them", yang artinya dengan membaca buku bermutu, seseorang memiliki keunggulan komparatif dibanding orang yang tidak membaca. Tujuan membaca permulaan adalah mengetahui hurufhuruf sekaligus membunyikan dan terampil mengubah huruf menjadi suara.

Berdasarkan uraian di atas, dapat disimpulkan membaca permulaan adalah adalah proses penyandian membaca secara recoding dan decoding yang dipengaruhi oleh faktor fonologis juga faktor fisiologis, intelektual, lingkungan dan psikologis.

\section{Pendekatan Whole Language}

Whole language adalah cara untuk menyatukan pandangan tentang bahasa, tentang pembelajaran, dan tentang orang-orang yang terlibat dalam pembelajaran. Whole language dimulai dengan menumbuhkan lingkungan dimana bahasa diajarkan secara utuh dan keterampilan bahasa (menyimak, berbicara, membaca, dan menulis) diajarkan secara terpadu. Menurut pendapat Weaver dalam Zuchdi (1996:108) pendekatan whole language adalah pembelajaran bahasa yang bersifat utuh atau menyeluruh, sesuai dengan kenyataan, dan gayut (relevan) dengan kebutuhan pembelajar, hal yang dipelajari harus bermakna dan ada kegunaannya, penggunaan bahasa yang dipelajari disesuaikan dengan situasi dan pembelajaran yang dipelajari harus menarik minat pembelajar. Pembelajaran bahasa secara utuh terkait dengan aspek keterampilan berbahasa hendaknya dipadukan dan tidak terpisah-pisah. Atau dapat dispesifikkan bahwa kemampuan yang perlu dikuasai berupa bahasa lisan (kemam- puan mendengar dan berbicara) dan bahasa tulis (kemampuan membaca dan menulis).

Selanjutnya Aminuddin (1994) menjelaskan bahwa whole language mengandung konsepsi bahwa bahasa merupakan gejala plural yang mempunyai keutuhan. Sebab itu, sebagai bahan pembelajaran, bahasa tidak dapat disikapi sebagai gejala yang tersegmentasikan secara artifisial melainkan disikapi sebagaimana gejala penggunaannya dalam berbagai peristiwa komunikasi. Sebagai wawasan yang ada dalam konteks pengajaran bahasa, penerapan prinsip whole language berimplikasi pada penyikapan bahasa sebagai bahan pembelajaran, bentuk pembelajaran, assessment, dan penilaian. Dalam artian luas, penerapan prinsip tersebut berimplikasi dalam perencanaan, pelaksanaan, dan penilaian program.

Brown (1997:25) memaparkan bahwa pendekatan terpadu menyarankan agar pengajaran bahasa Indonesia didasarkan pada wawasan Whole Language, yaitu wawasan belajar bahasa yang intinya menyarankan agar kegiatan pembelajaran bahasa Indonesia dilaksanakan terpadu antara membaca, mendengarkan, menulis, dan berbicara. Dengan konsep itu, dalam jangka panjang, target penguasaan kemahiran wacana itu bisa tercapai.

Eisele(1991:24-97) menyatakan bahwa prinsipprinsip pendekatan whole language sebagai berikut:

a. Anak tumbuh dan belajar lebih siap ketika mereka secara aktif mengajak dirinya sendiri untuk belajar.

b. Strategi dan kemahiran mereka pada proses kompleks seperti membaca dan menulis namun harus difasilitasi dengan baik oleh guru. Mereka perlu didukung secara psikologi.

c. Untuk membangun munculnya kemampuan membaca dan menulis, siswa perlu mencoba untuk meniru strategi orang tua atau guru

d. Pengajaran dengan whole language didasarkan pada pengamatan bawa banyak hal yang dipelajari pada diri siswa, sehingga guru perlu memberikan kesempatan dan mendorong ke dalam proses belajar.

e. Pembelajaran dengan whole language merangsang siswa untuk belajar secara mandiri. Tugas guru memberikan bimbingan kepada siswa.

f. Guru dan siswa bersama-sama belajar dan mengambil resiko serta mengambil keputusan bersama dalam belajar.

g. Guru mengenalkan interaksi sosial antara siswa, berdiskusi, berbagi ide, bekerja sama untuk menyelesaikan masalah yang dihadapi dalam belajar.

h. Guru memberikan materi kepada siswa berupa tes agar mampu membedakan kemampuan mana yang belum optimal serta mendorong siswa untuk menemukan dan mengkritik kelemahan sendiri.

i. Penilaian disatukan dengan pembelajaran.

j. Guru membangun dan mengembangkan jenis tingkah laku serta sikap yang diperlukan dalam kemajuan be- 


\section{FAHRURROZI}

lajar siswa.

Dalarn pembelajaran membaca permulaan merupakan salah satu kemampuan yang harus dimiliki sejak dini yang belangsung di kelas I dan II. Tujuannya agar dapat menyuarakan kalimat sederhana dan menjadi dasar pembelajaran membaca di kelas-kelas berikutnya khususnya dengan menggunakan pendekatan whole language agar pembelajaran lebih bernakna. Pengajaran tentang penggunaan tanda baca, umpamanya, diajarkan sehubungan dengan pembelajaran keterampilan menulis. Demikian juga pembelajaran membaca dapat diajarkan bersamaan dengan pembelajaran berbicara, pembelajaran sastra dapat disajikan bersamaan dengan pembelajaran membaca dan menulis ataupun berbicara.

Berdasarkan uraian di atas maka dapat disimpulkan pendekatan whole langrage adalah suatu bentuk pendekatan pembelajaran bahasa dengan menggabungkan kemampuan berbahasa sebagai satu kesatuan yang utuh antarkemampuan berbahasa yaitu kemampuan menyimak, berbicara, membaca dan menulis siswa. Pembelajaran ini dikenal juga dengan pembelajaran terpadu dengan model comnected.

\section{Simpulan}

Salah satu aspek pengajaran bahasa Indonesia di sekolah dasar yang memegang peran penting adalah membaca, khususnya membaca permulaan. Membaca permulaan terkait dengan bagaimana anak mampu mengenal huruf, suku kata, kata dan kalimat serta mampu melafalkannya dengan menggunakan suara yang jelas dan intonasi yang tepat. Pengajaran membaca permulaan dilakukan pada siswa SD kelas 1. Selama ini guru dalam mengajarkan membaca permulaan banyak menggunakan

\section{Daftar Pustaka}

Akhadiah, Sabarti, Pengembangan Budaya Keaksaraan melalui interwensi dini, Jakarta: Program pascasarjana IKIP, 1998.

Aminuddin. Whole Language dalam Pengajaran Bahasa. Seni dan Desain. Jurnal (Jakarta: http://journal.um.ac.id/index.php/seni-dandesain/article/ view/2235. 1994), h.4. Diuduh 08 September pu$\mathrm{kul} 10.56$

Anderson, R. C. Language Stills in Elementary Education. New York: Macmillan Publishing $\mathrm{Co}$, Inc, 1972.

Brown, H.D. Principles of Language Learning and Teaching. London: Prentice- Hall International Limited, 1997.

Dhieni, Nurbiana, dkk. Metode Pengembangan Bahasa. Jakarta: Universitas Terbuka, 2005.

Eisele, Beverly. Managing the Whole Language Classroom Creative Teaching Press, Inc., Cypress.1991.

Putra, R Masri Sareb, Menumbuhkan Minat Baca Sejak Dini. Jakarta: PT. Macanan Jaya Cemerlang, 2008.

Zuchdi, Darmiyatim dan Budiasih, Pendidikan Bahasa dan Sastra Indonesia di Kelas Rendah. Jakarta:Departemen Pendidikan dan Kebudayaan, 1996. berbagai pendekatan.

Salah satu pendekatan yang digunakan oleh guru dalam mengajarkan membaca permulaan adalah pendekatan whole language. Pendekatan whole language merupakan sebuah pendekatan di mana kompetensikompetensi berbahasa saling dihubungkan disaat pembelajaran berlangsung sehingga di dalam pembelajaran tersebut dapat mencapai tujuan yang telah ditentukan dalam proses belajar mengajar di sekolah secara optimal.

Subyantoro 2001. Membaca II. Jakarta : Universitas Terbuka. 2001 